\title{
PNEUMATOSIS INTESTINALIS: A RARE MANIFESTATION OF SYSTEMIC SCLEROSIS
}

Luiza Catharina Brusasco Grandini, ${ }^{1, \star}$, Júlia Yoneshigue Laranja de Oliveira1, Hany Kelly Araujo Cruz ${ }^{1}$, Marcus Vinicius de Jesus da Silva ${ }^{1}$, Lizeth Chaparro Del Portllo ${ }^{1}$,Mario Alberto Zarur Pérez ${ }^{1}$, Bruno Bordallo Corrêa ${ }^{1}$, Ludmila do Valle Vieira Gusmão ${ }^{1}$, Marco Antonio da Costa Nascimento ${ }^{1}$, Julio Cesar da Silva Borges ${ }^{1}$, Maria Isabel Dutra Souto ${ }^{1}$, Jose Angelo de Souza Papi ${ }^{1}$, Blanca Elena Rios Gomes Bica ${ }^{1}$

1.Universidade Federal do Rio de Janeiro, Rio de Janeiro (RJ), Brazil.

*Corresponding author: luiza_grandini@yahoo.com.br

\section{BACKGROUND}

Systemic sclerosis and dermatomyositis are disorders that affect multiple systems and organs, including the skin, lungs and intestines. Its ethology is unknown. The gastrointestinal tract is the most affected extracutaneous system in systemic sclerosis, occurring in $90 \%$ of patents, with dysmotility being a common manifestation. In dermatomyositis, disorders of motility of the tongue, pharyngeal musculature and proximal esophagus stand out, intestines may also be affected. Pneumatosis intestinalis (PI) is characterized by the presence of nematocysts in any segment of the intestinal wall and is a rare complication of the previously described pathologies.

\section{CASE REPORT}

Female, 29 years old, with the diagnosis of dermatomyositis, antisynthetase syndrome, systemic sclerosis, interstitial lung disease (ILD) and esophageal dysmotility since 2017. Comes to the hospital after 6 months showing signs of worsening of the skin thickening, diarrhea and weight loss of $15 \mathrm{~kg}$ other than epigastric pain and vomiting for 2 months. She was using azathioprine 100 $\mathrm{mg} /$ day and prednisone $2.5 \mathrm{mg} / \mathrm{day}$. An abdominal ultrasound was performed and showed hepatic steatosis and cholelithiasis. Digestive endoscopy was normal and computed tomography (CT) of the thorax and abdomen revealed pneumomediastinum and fluid-gas distension in the jejunum projection. Computed tomography enterography showed parietal gas distension of the jejunum, configuring intestinal pneumatosis (Fig. 1). Also, the presence of pneumoperitoneum in the pelvis among the mesenteric tributary vessels. Conservative treatment was started with antibiotic therapy, high-flow oxygen and parenteral nutrition. Computed tomography enterography was repeated revealing complete resolution 3 weeks later (Fig. 2).
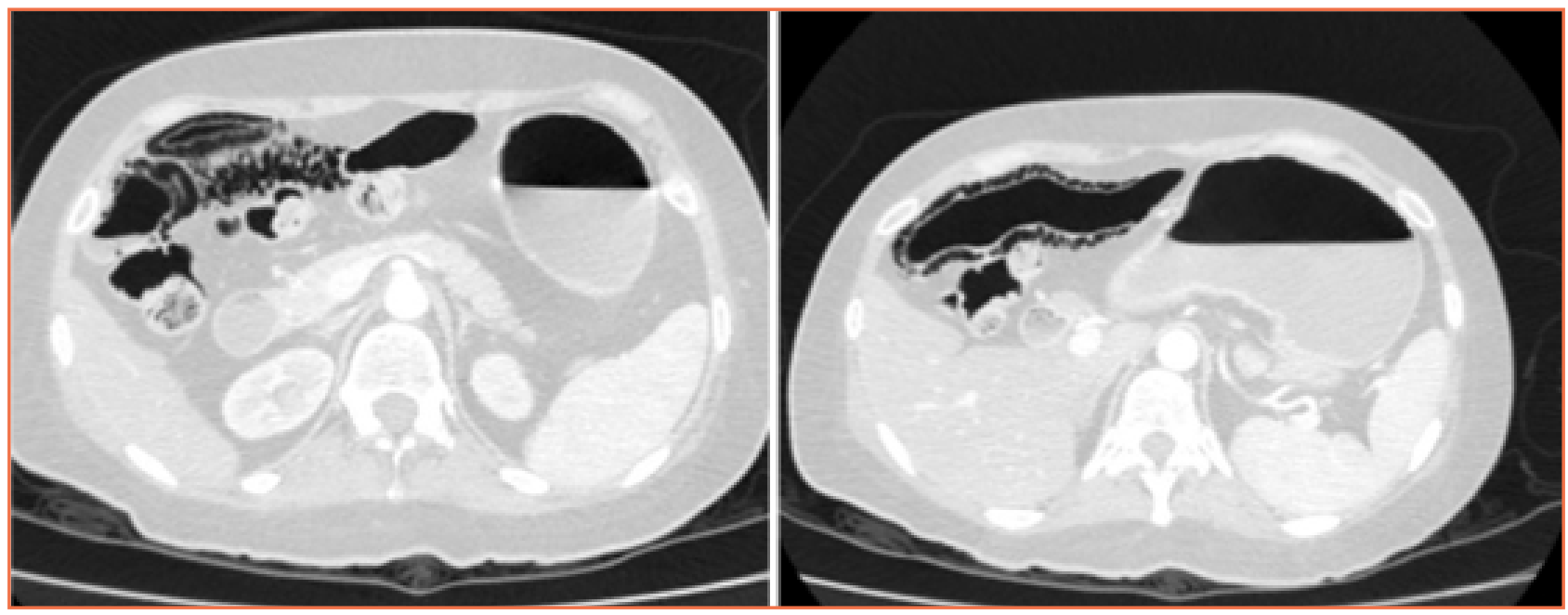

Figure 1. Computed tomography enterography showing pneumatosis intestinalis in a 28-year-old female patient with systemic sclerosis and dermatomyositis. 


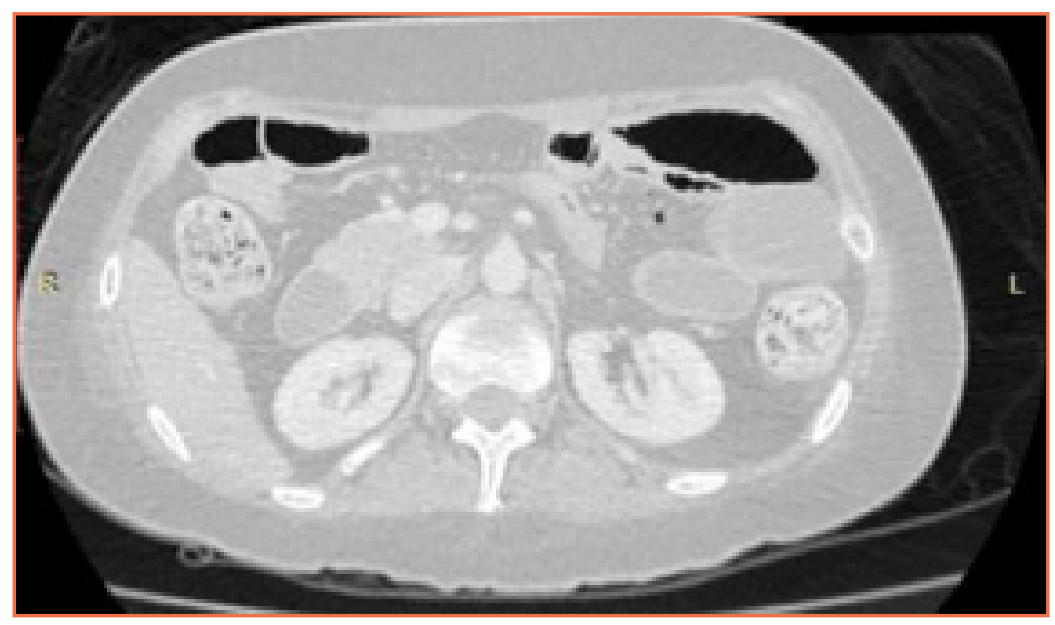

Figure 2. Computed tomography enterography after 3 weeks.

\section{CONCLUSION}

There are few reports of intestinal pneumatosis associated with autoimmune diseases of the connective tissue. Its etiopathogenesis is associated with four main theories: mechanical, bacterial, pulmonary and related to lesions of the intestinal mucosa. In our case, we highlight the mechanical and the bacterial mechanisms, correlated with dysmotility and the increase of the intraluminal pressure by gases, mainly hydrogen, produced by anaerobic bacteria present in the lumen. The pulmonary theory has probably contributed by the presence of DPI and pneumomediastinum, through gas diffusion along the vessels to the intestinal wall. In the approach of a patent with PI the evaluation of poor prognosis factors, early diagnosis and the institution of therapeutic measures are essential to a good outcome. 